\title{
Implications of Human Induced Changes on the Distribution of Important Plant Species in the Northwestern Coastal Desert of Egypt
}

\author{
Marwa Waseem Halmy ${ }^{1 *}$, Paul E. Gessler ${ }^{2}$, Selim Z. Heneidy ${ }^{1}$ \\ ${ }^{1}$ Department of Environmental Sciences, Faculty of Science, Alexandria University, Alexandria, Egypt, \\ 2 Department of Forest, Rangeland and Fire Sciences, P.O. Box: 441133, University of Idaho, Moscow, ID, \\ 83844-1133, USA., \\ ${ }^{*}$ Corresponding author, Email: marwa.w.halmy@alexu.edu.eg \\ Address: Department of Environmental Sciences, Faculty of \\ Science, P.O. Box: 21511, Alexandria, Egypt.
}

\begin{abstract}
The application of species distribution modeling in deserts is a useful tool for mapping species and assessing the impact of human induced changes on individual species. Such applications are still rare, and this may be attributed to the fact that much of the arid lands and deserts around the world are located in inaccessible areas. Few studies have conducted spatially explicit modeling of plant species distribution in Egypt. The random forests modeling approach was applied to climatic and land-surface parameters to predict the distribution of ten important plant species in an arid landscape in the northwestern coastal desert of Egypt. The impact of changes in land use and climate on the distribution of the plant species was assessed. The results indicate that the changes in land use in the area have resulted in habitat loss for all the modeled species. Projected future changes in land use reveal that all the modeled species will continue to suffer habitat loss.
\end{abstract}

The projected impact of modeled climate scenarios (A1B, A2A and B2A) on the distribution of the modeled species by 2040 is varied. Some of the species were projected to be adversely affected by the changes in climate, while other species are expected to benefit from these changes. The combined impact of the changes in land use and climate poses serious threats to most of the modeled species. The study found that all the species are expected to suffer loss in habitat, except Gymnocarpos decanderus. The study highlighted the importance of assessing the impact of land use/climate change scenarios on other species of restricted distribution in the area and can help shape policy and mitigation measures directed towards biodiversity conservation in Egypt.

Keywords - climate change - land use change - random forests - species conservation importance (SCl) index - species distribution models (SDMs).

\section{INTRODUCTION}

\section{A. Species Distribution Models (SDMs)}

Species distribution models (SDMs) were founded in ecology and natural history based on gradient modeling and niche theory [1], [2], [3]. Habitat or species distribution models (SDM) are defined as models that 'statistically relate the geographical distribution of species or communities to their present environment' [4]. Species distribution models (SDM) are also known as: bioclimatic models; climate envelopes; ecological niche models (ENMs); habitat models; resource selection functions (RSFs); and range maps [2]. The premise of these models is that environmental factors control the distribution of species and consequently communities [1], [4], [5].

Prediction of species distribution started early on by descriptive studies conducted by ecologists interested in understanding the relationship between patterns of species in relation to geographical settings and environmental gradients [2]. Later the evolution in ecology and other related fields coupled by the emergence of numerical analysis and quantitative approaches has greatly influenced species distribution modeling. Quantitative approaches of species distribution modeling developed as a result of convergence of two lines of research trends in ecology and geography. The first line started in ecology as field-based research that studied specieshabitat relationships. These studies later adopted quantitative approaches by applying statistical analysis techniques (e.g. linear multiple regression techniques), then the advanced regression 
techniques (e.g. Generalized Liner Models (GLMs) and boosted regression techniques) were developed to overcome limitations of the linear paradigm. The second line emerged in geography, and specifically in physical geography, through the advancement in geographic information systems and remote sensing techniques [2]. The integration of GIS and remote sensing has allowed the development of methods for interpolation of global climate and modeling global surface elevation, in addition to provision of spectral data that were employed in species prediction models. The development of the field of species distribution modeling and mapping has been driven by the need to map vegetation patterns over large areas for resource management and conservation planning, and to predict the effects of environmental changes on vegetation distribution [1], [5].

A suite of statistical and machine-learning techniques has been developed for conducting SDMs [6]. Although many approaches are used for the species distribution modeling, no rules exist to provide guidelines on the best modeling approach to use [3]. It is also likely that some approaches may be better for prediction of one species over another. This is related to many factors that include: the nature of the data used (quantity \& quality); the nature of the predicator variables used; the spatial scale used (resolution and the extent); and the relevance of the environmental predicators used to the ecological characteristics of the species being predicted [4], [7], [8], [9], [10].

\section{B. Applications of SDMs for Studying Global Changes}

The use and application of SDMs for different purposes is growing rapidly [11], because SDMs provide useful tools for understanding the gaps in knowledge of species distribution. More recently they have been used to assess potential impacts of changes in environmental and climatic conditions on the distribution of species [12], [4], [3], [13]. In most cases these studies deal with different land use/land cover and climatic scenarios.

The study by Sala and his colleagues [14] is one of the first studies that provided projection of changes in biodiversity at the global scale under different scenarios of climate and land use change by 2100 . The study provided scenarios of change in the ten widely known terrestrial biomes plus the fresh water aquatic ecosystems. They based their scenarios on how the change in some drivers (for example; climate, vegetation, land use, and levels of carbon dioxide) will trigger changes in biodiversity.

Over the last three decades, numbers of General Circulation Models (GCM's) have been developed. The Data Distribution Center (DDC) of the IPCC distributes a number of datasets, derived from various general circulation models (GCMs). These models are available on the web at: http://www.ipccdata.org/. Due to the coarse resolution of these data, they are mostly used to assess the potential impact of change in climate at a broad scale. This coarse resolution does not suit applications aiming at assessing the climate change impact on agriculture and biodiversity at finer scales [15], [16]. Therefore, many attempts have been made for downscaling and disaggregating GCM outputs (for example; [17], [16]). Spatial disaggregation based on WorldClim data [15] as baseline climate was applied to 24 different GCMs used in the IPCC4th assessment report for different emission scenarios and for seven different 30-year running mean periods [16]. The data are freely available through the CGIAR Research Program on Climate Change, Agriculture and Food Security (CCAFS) web: http://www.ccafs-climate.org/data/. The data have been used to assess the response of different species to the simulated changes in climate (for example, [18], [19], [20]).

Arid lands in general and deserts specifically, are poorly studied areas with regard to the assessment of their biodiversity and understanding the distribution of species in their vicinity [21]. This is likely related to the harsh nature of these areas and the inaccessibility of parts of the desert areas. The few studies that used species distribution modeling techniques in desert ecosystems were successful in providing tools for modeling the distribution patterns of species. Yet SDM approaches have rarely been used for addressing the influence of environmental changes (climate, land use change or any other disturbances) on the distribution of species in arid lands. This may be because arid lands are some of the most poorly studied areas in the world. Species distribution modeling techniques were used in the current study to project the impact of environmental changes on the distribution of ten important plant species in the northwestern coastal desert of Egypt. This region has experienced rapid change in land use/land cover recently due to coastal development projects. Species distribution modeling techniques and available environmental predictors (bioclimatic 
and land-surface parameters) were used here to: 1) predict the potential distribution of ten important plant species; 2) study the effect of land use change on distribution of the modeled species; and 3) project the potential changes in distribution of the species under different climate/land use scenarios.

\section{MATERIALS AND METHODS}

\section{A. Study Area}

The study area is part of the northwestern coastal desert of Egypt. It extends for $40 \mathrm{~km}$ from El-hamam town to westward to El-Alamein town and from the Mediterranean coast southward to Moghra Oasis (Figure 1), occupying an area of about $2800 \mathrm{~km} 2$ located between $30^{\circ} 10^{\prime}$ to $30^{\circ} 55^{\prime}$ and $\mathrm{N} 28^{\circ} 55^{\prime}$ to $29^{\circ} 25^{\prime} \mathrm{E}$.

The area has a short rainy season, which occurs mostly during winter from November to April but may extend to May. Little precipitation occurs during the rest of the year [22], [23]. The mean annual precipitation ranges from 100 to $150 \mathrm{~mm} /$ year, thus the area considered arid (rainfall zones of 0-300 $\mathrm{mm}$ ) [24]. The climatic records [25] indicate that the total monthly evapotranspiration in the coastal area exceeds the total annual precipitation. This reflects the arid conditions and the water deficiencies that prevail in the area. A north-south climatic gradient was noticed in this region, with an increase in environmental aridity and 'thermal continentality' towards the South [26]. The vegetation of the region is dominated by dwarf shrubs less than one meter [24]. The agricultural activities in the northern part have resulted in changes throughout the area that might have impacted species distributions.

The Omayed Biosphere Reserve (OBR) a.k.a. ElOmayed Protected Area (OPA) is located in the northern part of the study area (Figure 1). The protected area is considered as one of the largest terrestrial protected area in Egypt [27].

\section{B. Data Collection}

Field visits were conducted to survey the plant species in the area, where more than 800 plots were selected randomly in order to account for the major physiographic variation in the study area. Plant species were recorded and identified according to "Students' Flora of Egypt" by Täckholm [28] and nomenclature of the species was updated following
"Flora of Egypt" by Boulos [28], [29], [30], [31], [32] and the Latin names of the species were updated following the "Flora of Egypt: Checklist" by Boulos [33]. Species distribution modeling could be developed based on the presence-only data or presence-absence data [35]. In the current study, both presence and absence data were employed in modeling.

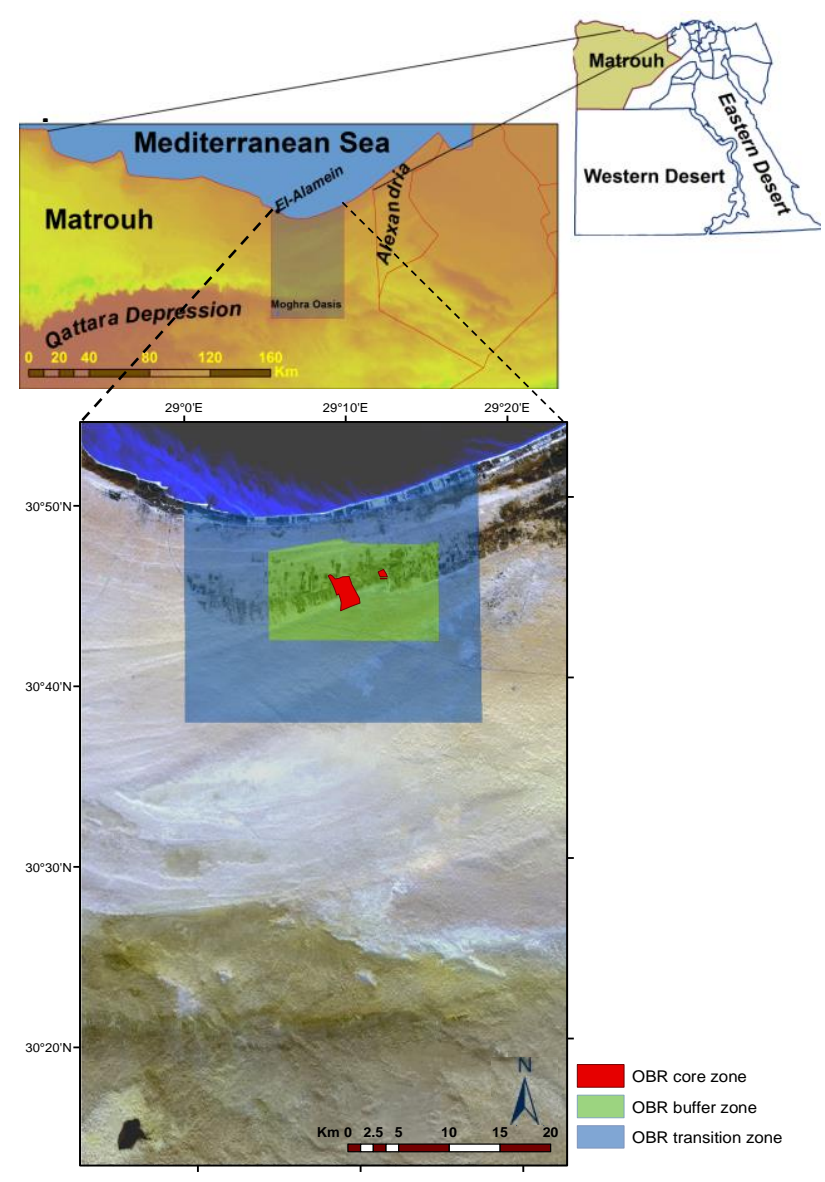

Fig .1. Location of the studied area: a) Egyptian governorates' administrative boundaries; b) the northwestern coastal desert showing location of the study area northeast of Qattara Depression; and c) the study area as shown through part of Landsat Thematic Mapper 2011 image. The location of Omayed Biosphere Reserve (OBR) is highlighted, core zones in red, buffer zone in green and transition zone in blue (After [34]).

\section{Predictors}

The accuracy and the predictive power of any habitat distribution model depend on the quality and the accuracy of the field data employed and the choice of the environmental variables used to build the model [40]. In the current study, a number of land-surface parameters and bioclimatic variables were used to build the plant species distribution models (Table 1). Ecological land-surface parameters derived from 
digital elevation models (DEMs) are considered important for mapping vegetation, especially if combined with other parameters including spectral indices derived from satellite imagery [41]. A digital elevation data SRTM V4.1 (Jarvis et al. 2008) were used for the derivation of land-surface parameters. The land-surface parameters employed in the study (Table 1) included slope; a terrain roughness index (TRI) that provides an quantification of the level of undulation and the complexity of the surface [42]; topographic wetness index (TWI) [43]; and a slope length and steepness (LS) factor. All the land-surface parameters were derived using the Automated System Geoscientific Analyses version 2.0.7 [44].

Climatic conditions are recognized as the most important environmental variables responsible for the patterns of species distribution at broad scales [45]. However, the availability of climatic data layers of appropriate resolution has been rare for researchers intending to do species distribution mapping, especially in understudied areas [3]. Recently, interpolated global climatic data layers that represent the previous and current climatic conditions were made available to the public (for example; WorldClim [15] and CliMond [46]). 'WorldClim' is available with global coverage at a spatial resolution of $1 \mathrm{~km} 2$ and can be downloaded from http://www.worldclim.org. The WorldClim data include monthly mean total precipitation and mean, minimum, and maximum temperature in addition to nineteen other bioclimatic variables. The current study used thirty environmental variables (Table 1) representing important factors for plant survival; including bioclimatic variables, topographic variables and light controlling factors. The incorporation of light controlling factors in modeling plant distribution was recommended, particularly in studies that involve assessment of the impact of climate change on plant distribution [47]. Solar insolation indices were derived from the digital elevation data and included in the analysis. The distance to the coast was also included as a factor in modeling plant species distribution to account for maritime influences due to proximity to the Mediterranean Sea. All the layers representing the variables employed in the analysis were re-sampled to match the spatial resolution of the DEM used.

\section{Modeling Approach}

The data used in the current study were collected systematically using field surveys through which the presence/ absence observations were recorded for each species. Generalized linear models (GLMs) or ensembles of regression trees such as random forests (RF) or boosted regression trees, (BRT) are recommended in cases where presence/absence data are available [3], [48], [6]. The current study applied the machine learning ensemble method random forests (RF) to predict the distribution of the selected species using climatological and topographical factors. The collected presence/absence data were divided randomly to two sets; $70 \%$ for calibrating the models and $30 \%$ for testing and evaluating the models. All the analyses were conducted within the framework of the open source statistical computing environment of $R$ 2.13.1 [49]. The 'randomForest' package [50] was used for carrying out the random forests analyses. Random forests analysis (RF) has been used in some studies for modeling species and predicting changes in species distribution under different climate scenarios [51], [52], [10], [53], [54]. It is one of the 'ensemble modeling' techniques that have recently been used successfully in ecological modeling [3]. It is composed of an ensemble of [55] classification and regression trees (CART) [56]. The RF approach has the advantage of being a nonparametric approach that can produce a highly accurate classification results and can process a larger number of independent variables [57]. It has been recommended for being robust to outliers and noise [57], [58], [59], [56], [60], [61].

In RF model, an ensemble of classification and regression tree (CART) models is created by training each model on a bootstrap sample of the original training data set. The output from each CART model is then subjected to a voting process whereby the most common vote is selected for producing the final results of a classification and the average of all the tree results is obtained in the case of performing regression. The size of the random forests model (i.e. the number of trees) and the number of variables to be used for splitting nodes at each tree in the random forests model need to be specified by the analyst depending on the study. The selection of these parameters is based on the combination that minimizes the out-of-bag error (oob). Out-of-bag error estimation is used as an assessment of the accuracy of the model. It is estimated by keeping out (out-ofbag) one third of each bootstrap replica generated from the original training data and using it to test the tree models. The use of oob error for evaluating the performance of the RF models is considered a robust 
unbiased method [57]. The optimum combination of the number of trees in the RF model and the number of variables to be used for splitting nodes was determined based on trials, which revealed that models with a size of 750 trees and four splitting variables at each node attained the lowest error rates. A general model for predicting each species was fit using all the variables, whereby an assessment of the importance of each variable in fitting the model was estimated. The percentage of increase in mean square error (MSE) was caused when a variable that is randomly permuted and introduced to the model was used as basis for selection of variables to create a reduced model for each species.

Table 1. Variables used in building the models of species distribution in the study area.

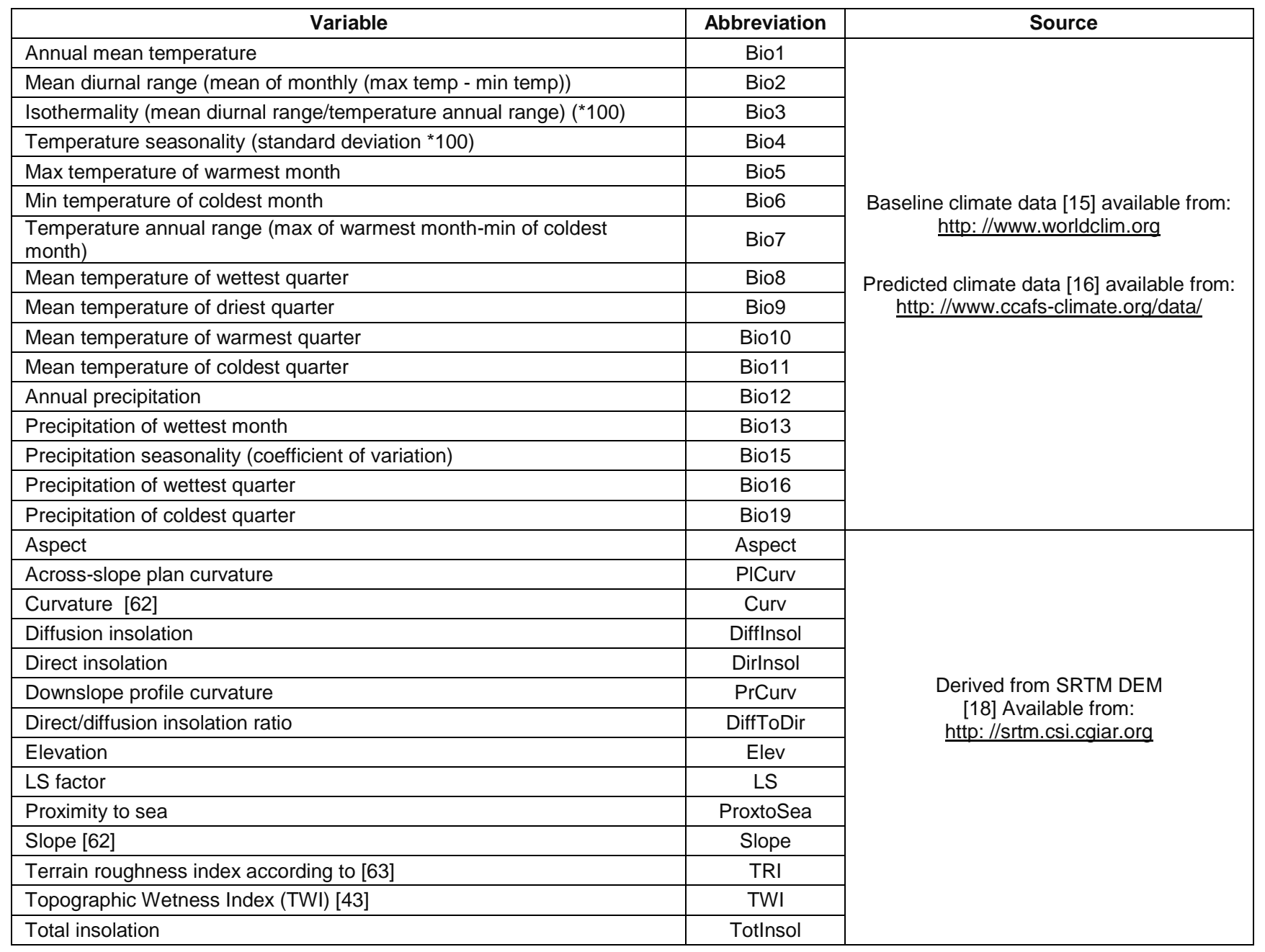

\section{E. Models Evaluation}

The accuracy and credibility of habitat distribution models should be considered in the context of the intended applications [4]. Accuracy assessment and uncertainty about the data used in developing these models should be reflected in and accounted for by any further analysis that might use the products of these models [64]. An account of the most commonly used measures for accuracy assessment of the species distribution models can be found in [3], [11]. The most commonly used threshold-dependent measure for assessing accuracy of habitat distribution models is the Kappa statistic; however kappa has been criticized for producing a biased accuracy assessment. Allouche and colleagues [65] described the bias encountered when using Kappa statistic [66] and suggested using the true skill statistic (TSS) [67] as an alternative method for assessing the accuracy of habitat distribution models. In the current study, both Cohen's kappa and the TSS are used as threshold-dependent measures in assessing the accuracy of the produced models along with the overall accuracy, sensitivity (the proportion of the correctly predicted presence observations), and specificity (the proportion of the correctly predicted 
absence observations). The threshold-independent area under the receiver operating curve (AUROC) [68] was also used to assess the accuracy of the models.

kappa

$$
\begin{gathered}
=\frac{\left(\frac{a+b}{n}\right)-\frac{(a+b)(a+c)+(c+d)(d+b)}{n^{2}}}{1-\frac{(a+b)(a+c)+(c+d)(d+b)}{n^{2}}} \\
T S S=\left(\left(\frac{a}{a+c}\right)+\left(\frac{d}{b+d}\right)\right)-1
\end{gathered}
$$

Where $a$, number of test presence records which were correctly predicted by the model; $b$, number of test absence records which the model predicted as presence; c, number of test presence records which the model predicted as absence; $d$, number of test absence records that were correctly predicted by the model; $n$, the total number of the test records.

\section{F. Studying the Combined Impact of Land Use and Climate Change}

Species distribution modeling is used frequently to predict the potential changes in species distribution under different change scenarios [48], [47]. Prediction of the potential shift in plant distribution under different climate change scenarios is considered as one of the important applications of the species distribution models [69], [47]. Most of the studies that project the impact of climate change on species distributions have been applied on global or regional scales (for example; study by Sala and colleagues [14], and study by Skov and Svenning [70]). However, there is a need for applying the same principles at the landscape level which will be of great help to conservation efforts at this scale [71]. The information provided by such tools is considered crucial for decision making related to land management and conservation planning [72], [4]. Most of the studies that have predicted the potential change in plant species under climate change scenarios have focused on temperate regions (for example; [45], [73], [71]). The current study provides an assessment of the potential impact of climate change on the distribution of ten plant species in a desert ecosystem.

Mapping the distribution of all the species recorded in the study area is a lofty goal that cannot be achieved in one single study due to the insufficiency of the occurrence records and additional logistical challenges. To overcome this problem, the current study sought to focus on predicting the distribution of 'important' species with sufficient occurrence records. Important species were defined as those serving crucial functions and providing important services in any ecosystem. This could include, for example, sand stabilizing and nitrogen-fixing plants. Many of the species recorded in the coastal area are considered 'multipurpose' species providing multi-use for local inhabitants [36], [37]. The current study focused on ten important species based on their importance values as indicated by the Species Conservation Importance (SCI) [38] and the number of occurrence records for each species. The value of the index includes information related to the conservation status, commonness, biological type, and utilitarian value of each species. The value of the $\mathrm{SCl}$ are in the range from 0.2 to 1 , with values approaching 1 indicating species with high importance value and those approaching 0.2 indicating species with a low importance value [38], [39]. The species with SCI value of 0.55 or more and sufficient number of occurrence records $(>100)$ were modeled.

Land use/land cover maps representing different dates (1988, 2011 and projected 2023) were used to assess the impact of land use change on the distribution of the ten modeled plant species [34]. Each of these LULC maps represents a different stage of human influence on the landscape, with an increase in human impact with time. The maps were reclassified into two categories only to create digital Boolean layers. Natural areas category represent all the areas that have not been transformed by human activities and the man-made category that includes all the artificially created areas (For example urban, roads, orchards and croplands). The natural areas were assigned values of one, while those considered man-made were assigned values of zero. The Boolean layers representing each date were multiplied by the layers that represent the potential distribution of each of the modeled ten species. Thus the reduction or the expansion in the area occupied by each species under each land use scenario was estimated.

For projecting the potential distribution of the ten species of interest under different climatic scenarios, predicted climate changes according to the CSIRO Mk 2.0 \&Mk3.0 GCMs [74] were employed. These models are used to represent the predicted climate over the period 2010-2040 under different emission scenarios; 
$\mathrm{A} 2 \mathrm{~A}$ and $\mathrm{B} 2 \mathrm{~A}$ are high greenhouse emission scenarios, while $A 1 b$ is a medium emission scenario. The data were retrieved from the CGIAR Research Program on Climate Change, Agriculture and Food Security (CCAFS) web: http://www.ccafsclimate.org/data/. The projected distribution of the plant species in the study area according to the used climate scenarios were compared to their potential distribution under the baseline climate. Twelve scenarios were developed for each species (Table 2) to estimate the change in species habitats under the combined impacts of changes in land use and climate. The increases and the decreases in the habitat area for each species under the different scenarios were estimated.

Table 2. Scenarios of climate and land use change used in the study. The annual mean temperature and the annual precipitation predicted for the period 2010-2040 by each climate change scenario are compared to the baseline climate that represents an average for the period $1950-2000$ [15]

\begin{tabular}{|c|c|c|c|}
\hline \multirow[b]{2}{*}{ Climate change scenarios } & \multicolumn{3}{|c|}{ Land use change scenario } \\
\hline & $\begin{array}{c}\text { No land use } \\
\text { Natural landscape } \\
(1)\end{array}$ & $\begin{array}{c}\text { Current land use scenario } \\
(2011) \\
(2)\end{array}$ & $\begin{array}{c}\text { Simulated future scenario (2023) } \\
\text { (3) }\end{array}$ \\
\hline a) Average Climate (1950-2000) & Baseline climate/Natural & Baseline climate/2011 & Baseline climate/2023 \\
\hline b) A1B (+1.03 $\stackrel{\circ}{ } \mathrm{C} \&-12.23 \mathrm{~mm})$ & A1B/ Natural & $\mathrm{A} 1 \mathrm{~B} / 2011$ & $\mathrm{~A} 1 \mathrm{~B} / 2023$ \\
\hline 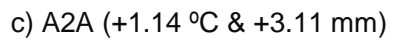 & A2A/ Natural & $\mathrm{A} 2 \mathrm{~A} / 2011$ & A2A/2023 \\
\hline d) $B 2 A(+1.28 \stackrel{\circ}{ } \mathrm{C} \&-6.34 \mathrm{~mm})$ & B2A/ Natural & $\mathrm{B} 2 \mathrm{~A} / 2011$ & $\mathrm{~B} 2 \mathrm{~A} / 2023$ \\
\hline
\end{tabular}

\section{RESULTS\& DISCUSSION}

\section{A. Species Distribution}

A total of 244 species were recorded in the study area, out of which $57 \%$ are perennials, $38 \%$ are annuals and the remaining are biennials or short lived perennials. Species recorded in the study area belong to fifty taxonomic families. Compositae (Asteraceae), Gramineae, Leguminosae (Fabaceae) and Chenopodiaceae are contributing the most to the flora of the region; this is in accordance with the study by Shaltout [75].The use of SII facilitated the selection of the species based on their importance. The distribution of 10 out of the 244 species recorded in the study area was modeled (Table 3 ).

Eight models out of the ten attained an area under the curve (AUC) value over 0.7 , which indicates that these models are of moderate performance [76]. Astragalus spinosus and Stipagrostis obtuse models attained AUC values exceeding 0.65 , which indicates that the models are better than random. Based on kappa values, Astragalus spinosus, Echinops spinosus, and Stipagrostis obtuse models are considered of poor performance as they had kappa values less than 0.4 (Table 3). The models of seven species out of the ten performed fairly well as indicated by all the used measures of accuracy assessment. Both models of
Haloxylon salicornicum and Noaea mucronata exhibited good performance with kappa and TSS exceeding 0.5 , AUC above 0.8 , and overall accuracy above $81 \%$.

The accuracy and the predictive power of any species distribution model depends on the quality and the accuracy of the field data employed and the choice of the environmental variables to be used in the model [40]. Taking into account the limitation of the resolution of the environmental data employed in the study, particularly the climatic variables used for predicting the distribution of species in the study area, the results obtained are considered acceptable. The availability of high resolution environmental predictors is important for modeling the distribution of species at landscape scales [77], [47]. Such high resolution environmental data is difficult to obtain for the poorly studied areas. The deficiency in geographic databases (topographic and climatic databases) representing areas in developing countries and underdeveloped areas was and is still one of the major problems that faces researchers.

The pattern of species distribution is often related to a number of environmental variables. Predictive models of species distribution could include variables selected based on a theoretical basis following conceptual model [78]. The conceptual framework for modeling 
plant species suggested by Franklin [1] was revisited by Austin and Van [47]. They emphasized including environmental predictors that are considered direct factors influencing plant growth and distribution. This included light, temperature, nutrients, water, carbon dioxide and biotic interaction.

Although it is important to include the variables that correlate to the species distribution and also show meaningful biological relationships [78]; some studies fail to include some factors of importance. Austin and Van [47] highlighted the need for inclusion of light as a predictor in models predicting distribution of plant species, which has been overlooked by many studies. They argued that light as a predictor has an important influence on distribution of plant species. In the current study, light was included in modeling species of the study area expressed as total insolation, direct insolation, diffusion insolation, and direct/diffusion insolation ratios. Each of these factors was found to be important for modeling plant species in the study area. Diffusion insolation was found to be important for predicting all the species except for Echinops spinosus, for which direct insolation was found important (Table 4). Austin and Van [47] maintained that the difference in light regime between north and south-facing aspects can result in differences in temperature equal to that resulting from a shift of 200 $\mathrm{km}$ in latitude.

Table 3. The modeled important plant species selected out of the 244 species recorded in the study area; abbreviations used; estimated species importance index (SII) values; number of occurrences recorded in the study area; and the measures used to assess the accuracy of the random forests models predicting their distribution. Accuracy assessment measures presented are: Sensitivity; Specificity; True skill statistic (TSS); Cohen's Kappa statistic; the overall accuracy; and the area under the curve (AUC) statistic of the receiver operating characteristic (ROC).

\begin{tabular}{|c|c|c|c|c|c|c|c|c|c|}
\hline Species & Abbreviation & SII & $\begin{array}{l}\text { Number of } \\
\text { occurrences }\end{array}$ & Sensitivity & Specificity & TSS & Kappa & Accuracy & AUC \\
\hline $\begin{array}{c}\text { Anabasis } \\
\text { articulata } \\
\text { (Forssk.) Moq. }\end{array}$ & Ana_art & 0.72 & 454 & 0.92 & 0.509 & 0.429 & 0.447 & 73.790 & 0.790 \\
\hline $\begin{array}{l}\text { Asphodelus } \\
\text { aestivus Brot. }\end{array}$ & Asp_aes & 0.64 & 119 & 0.533 & 0.882 & 0.415 & 0.405 & 81.855 & 0.828 \\
\hline $\begin{array}{c}\text { Astragalus } \\
\text { spinosus } \\
\text { (Forssk.) } \\
\text { Muschl. }\end{array}$ & Ast_spi & 0.64 & 137 & 0.442 & 0.784 & 0.226 & 0.191 & 72.470 & 0.664 \\
\hline $\begin{array}{c}\text { Deverra } \\
\text { tortuosa (Desf.) } \\
\text { DC. }\end{array}$ & Dev_tor & 0.76 & 212 & 0.589 & 0.828 & 0.417 & 0.417 & 75.709 & 0.764 \\
\hline $\begin{array}{l}\text { Echinops } \\
\text { spinosus L. }\end{array}$ & Ech_spi & 0.64 & 103 & 0.489 & 0.847 & 0.335 & 0.314 & 78.138 & 0.703 \\
\hline $\begin{array}{c}\text { Gymnocarpos } \\
\text { decanderus } \\
\text { Forssk. }\end{array}$ & Gym_dec & 0.64 & 250 & 0.835 & 0.62 & 0.455 & 0.401 & 69.355 & 0.744 \\
\hline $\begin{array}{c}\text { Haloxylon } \\
\text { salicornicum } \\
\text { (Moq.) Bunge ex } \\
\text { Boiss. }\end{array}$ & Hal_sal & 0.6 & 184 & 0.709 & 0.845 & 0.554 & 0.507 & 81.452 & 0.840 \\
\hline $\begin{array}{c}\text { Noaea } \\
\text { mucronata } \\
\text { (Forssk.) Asch. } \\
\text { and Schweinf. }\end{array}$ & Noa_muc & 0.56 & 211 & 0.73 & 0.849 & 0.579 & 0.547 & 81.855 & 0.872 \\
\hline $\begin{array}{c}\text { Stipagrostis } \\
\text { obtuse (Delile) } \\
\text { Nees }\end{array}$ & Sti_obt & 0.56 & 208 & 0.651 & 0.697 & 0.348 & 0.296 & 68.548 & 0.671 \\
\hline $\begin{array}{l}\text { Thymelaea } \\
\text { hirsuta (L.) } \\
\text { Endl. }\end{array}$ & Thy_hir & 0.76 & 300 & 0.784 & 0.682 & 0.466 & 0.444 & 72.177 & 0.789 \\
\hline
\end{tabular}


Table 4. Variables selected for the predictive models for each species based on the percentage increase in MSE when a given variable was randomly permuted and introduced into the model. See Table 1 for variable abbreviations and Table 3 for species binomial abbreviations.

\begin{tabular}{|c|c|c|c|c|c|c|c|c|c|c|}
\hline Variable & Ana_art & Asp_aes & Ast_spi & Dev_tor & Ech_spi & Gym_dec & Hal_sal & Noa_muc & Sti_obt & Thy_hir \\
\hline Bio2 & + & + & + & + & + & + & + & & + & + \\
\hline Bio3 & + & + & & & & & & + & + \\
\hline Bio4 & + & + & + & + & + & + & + & + & + & + \\
\hline Bio12 & + & + & + & + & + & + & + & & & + \\
\hline Bio13 & & + & & & & & & + & & + \\
\hline Bio15 & & & & & & & & & & + \\
\hline Bio16 & + & + & + & + & + & + & + & + & + & + \\
\hline Bio19 & & + & & & + & & & & & + \\
\hline ELv & + & + & + & & + & + & + & + & + & + \\
\hline LS & & & + & & & & & + & & + \\
\hline Slope & & & & + & + & & & & + & + \\
\hline TRI & & & + & + & & & & & + & + \\
\hline TWI & & + & + & + & + & & & + & + & + \\
\hline ProxtoSea & + & + & + & + & + & + & + & + & + & + \\
\hline Difflnsol & + & + & + & + & & + & + & + & + & + \\
\hline Dirlnsol & & + & + & + & + & & & & + \\
\hline DiffToDir & & + & + & + & & + & + \\
\hline
\end{tabular}

In the current study, generally seventeen out of the original thirty environmental variables contributed to the modeling of the species in the study area. Of the climatic variables, the mean of temperature diurnal range, temperature seasonality, annual precipitation and precipitation of the wettest quarter were the common climatic factors in controlling the distribution of most the modeled species (Table 4). Climatic variables representing annual cycle (for example annual mean temperature and annual precipitation) seem to control the general vegetation cover over the broad scale.

Bornkamm and Kehl [24] divided the western desert into five zones characterized by different vegetation cover and plant communities based on the mean annual rainfall. The study area falls within Zone I and Zone II of this classification. The vegetation cover of Zone I (semi-desert with mean annual rainfall $>20$ $\mathrm{mm}$ ) is composed of dwarf shrubs dominated by Thymelaea hirsuta. Zones II and III are full-desert (with mean annual rainfall $10-20 \mathrm{~mm}$ ) with communities dominated by Asphodelus microcarpus and Plantago albicans. Climatic factors that represent seasonality (e.g. mean of temperature diurnal range, temperature seasonality and precipitation of the wettest quarter) are more important for the distribution of the species at local scales as is suggested by the results of the current study. The results indicate that the land-surface parameters are of influence on the distribution of species. Topographic factors such as elevation, diffusion insolation, direct insolation, and topographic wetness index were found to be important in predicting most of the modeled species (Table 4). Hammouda [79] in a study focusing on the Omayed area (part of the study area) found that species distribution and plant community composition are influenced by topography, the nature and origin of the parent material, in addition to the land use and degree of human intervention. Land-surface parameters controlling moisture availability were found to be of importance for species distribution by some studies that focused on assessing the quantitative relationships between environmental variables and vegetation in the northwestern desert (for example; [80], [81], [82], [83]). Ayyad and Ammar [81] found that abundance and the distribution of the perennials are more affected by factors controlling moisture availability through run-off; such as slope and curvature. Ayyad and Ammar [84] also, found factors controlling moisture availability (for example; slope inclination, topographic position, nature of surface, soil depth and soil texture) which are the most important in controlling vegetation composition in the area. Ayyad and El-Ghareeb [83] found that the micro-variations in the soil were attributed to variations in topography and 
the nature of parent materials on the distribution of species in the area. The results of the current study also showed that the proximity to sea is one of the common important factors for predicting all the modeled species. Communities of the coastal dunes dominated by Echinops spinosus and Thymelea hirsuta and those of the inland ridges dominated by Gymnocarpos decanderus and Deverra tortuosa are stated to be the most diverse in the area [85]. However, these communities are stated to be threatened due to the establishment of summer resorts on the coastal dunes and the establishment of the irrigation network on the non-saline depressions [86].

\section{B. Effect of Climate and Land Use Changes on Species Distribution}

\section{Effect of land use change}

Species distribution models are increasingly used for prediction of the potential distribution of the species in response to disturbance or changes resulting from human intervention. Predictive habitat distribution models are used as important tools for assessing the impact of land use change and other forms of human interference on different species. Habitat distribution models have proven to be useful for modeling both commonly distributed species [87] as well as rare species [12], [54]. Some studies used models with AUC values $>0.6$ for projecting the impact of climate change on plant distribution [71]. However, the intention here was to be more conservative and use only the models that showed reasonable performance according to all the accuracy assessment measures to assess the impact of both land use and climate change. As a result, only seven species were mapped to assess the impact of change in land use on their distribution (Figure 2). Assessment was done by comparing the area occupied by each species under no land use change in the area (theoretically natural landscape) to that in the years 1988 and 2011. The results show that all species face reduction in their habitats (Figure 3). The results also show that all the species are at risk for increased reduction of their habitats under the projected land use change by the year 2023.

Noaea mucronata attained the maximum loss in habitat area in 1988 (7.47\% of the potential area; Figure 3), this increased five folds by 2011 (37.74\%) and six folds by 2023 (44.79\%). The major loss for this species occurs between the years 1988 and 2011. This trend is noticed for all the modeled species. Halmy and colleagues [34], [38] assessed the change in the landscape between the years 1988 and 2011 and found that the landscape has experienced changes by which many natural areas were transformed to new uses. The study concluded that the landscape is trending towards being more artificial. This explains the dramatic increase in loss of areas occupied by each species between the years 1988 and 2011. The projected loss in the species' area between the years 2011 and 2023 was shown to be lower than that between 1988 and 2011. Noaea mucronata, Asphodelus aestivus, and Deverra tortuosa (Figure 3 ) are most affected by the changes in land use in the period 1988-2011 and will continue to be at risk of habitat loss by the year 2023. The distribution of these three species is concentrated in the northern part of the landscape. This part of the landscape has been the most modified by human activities, and will continue to face more modifications pressures in the future.

The urban sprawl, agricultural activities and other activities occurring in the area have resulted in habitat loss. These recent changes in the region place the plant species and their habitats under threat. In the late 1980s, establishment of summer resorts on the coastal dunes started to reshape the landscape of the area. Quarrying activities increased as a result of the establishment of these resorts. Mining and cutting of the limestone ridges in the area provide building materials necessary for the establishment of the resorts. This may have contributed to the fragmentation, destruction and loss of habitats. Species inhabiting the coastal dunes and the non-saline depression habitats are stated to be threatened due to the establishment of summer resorts on the coastal dunes and the establishment of the irrigation network on the non-saline depression [86]. Factors such as habitat size reduction or habitat fragmentation represent the most serious causes of species loss. However, arrangement and connectivity of habitat patches are also of great importance. Habitat fragmentation makes it difficult for wildlife to maintain stable populations [88], [89]. The current study did not assess the fragmentation in the habitat of each species or estimated the degree of connectivity among patches. This will be part of future work planned to include more species with restricted distribution in the area. 

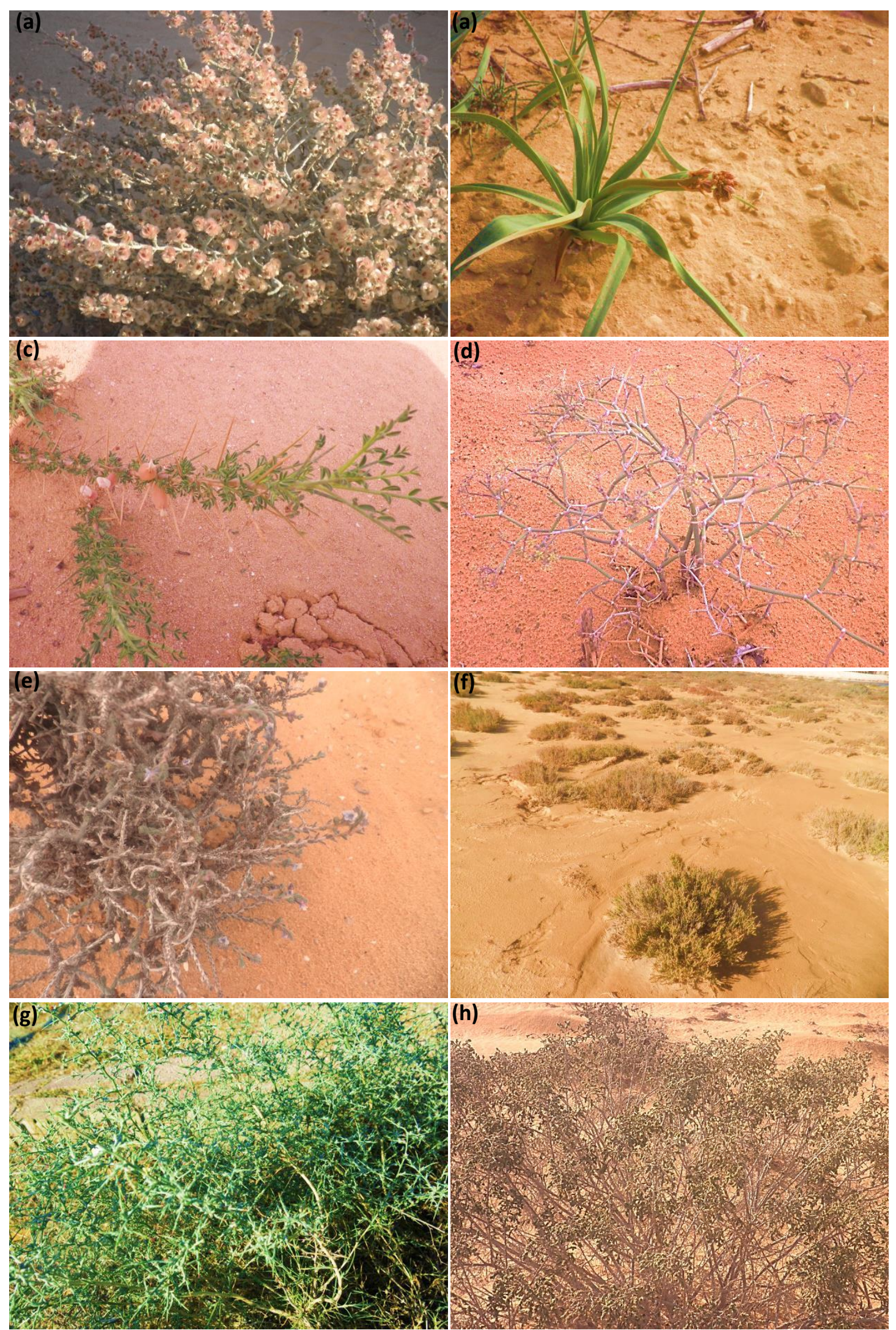

Fig .2. Some of the species modelled; (a) Anabasis articulata, (b) Asphodelus aestivus, (c) Astragalus spinosus, (d) Deverra tortuosa, (e) Gymnocarpos decanderus, (f) Haloxylon salicornicum, (g) Noaea mucronata, and (h) Thymelaea hirsuta. 


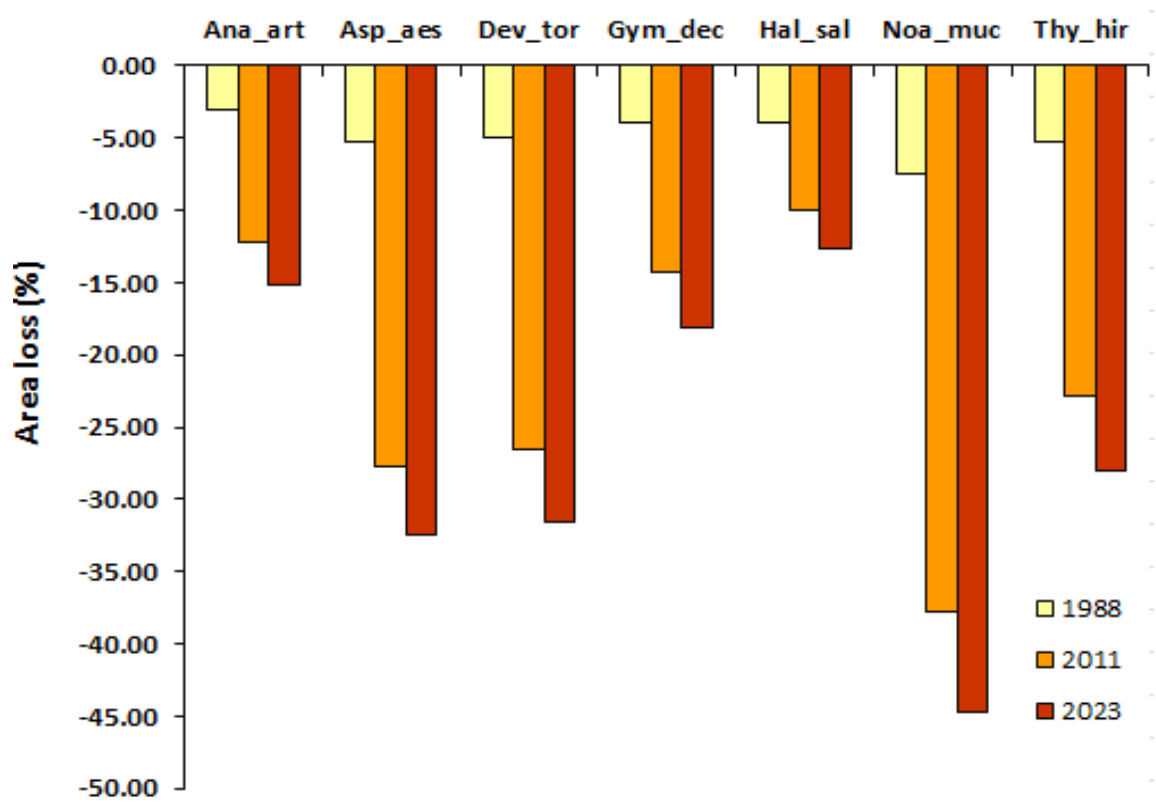

Fig .3. Change in habitat area due to change in land use in 1988, 2011, and the projected change by 2023. The loss is expressed as percentage of the potential habitat area for each species under the baseline climate and no land use. See Table 3 for species binomial abbreviations.

\section{Effect of climate change}

Many studies have focused on projecting the impact of climate change on the distribution of plant species [45], [90], [14], [73], [91], [92], [71]. Most of these studies have been applied on global or regional scale. The current study attempts to assess the potential impact that climate change might have on the distribution of some plant species at the landscape scale within a desert ecosystem.

Under the CSIRO GCM models, the different emission scenarios used in the current study are predicted to lead to changes in the temperature and precipitation of the area (Table 2 \& Figure 4). The study area is expected to experience an increase in annual mean temperature under the three applied scenarios, with B2A expected to result in the highest increase in temperature. Not all the scenarios predict reduction in the annual mean precipitation of the area. The area is expected to experience increase in the annual mean precipitation by $3.11 \mathrm{~mm}$ compared to the average over the period 1950-2000 under the A2A scenario. Climate has an influence on species distribution at broad scale [45], [93]. The results show that at the landscape level and the change in climate under the different emission scenarios have resulted in changes in the modeled species distribution. Although the differences among the climate scenarios developed by the different models up to 2050 are stated to be minor [94], [95], the current results show that the expected impact of each of the used climate scenarios on the modeled species is different (Figure 4).

Noaea mucronata, Asphodelus aestivus, and Anabasis articulataare are expected to be at risk of loss of habitat under all the employed scenarios. The high emission scenarios B2A and A2A cause higher impact on these species compared to the low emission scenario (A1B). For example, under B2A Noaea mucronata, Asphodelus aestivus, and Anabasis articulata are expected to lose about $96 \%$, $58 \%$ and $17 \%$ of their potential area respectively, while under A1B each are expected to lose $85 \%$, $29 \%$, and $13 \%$ of their potential area respectively (Figure 5). Scenario A1B, on the contrary, is expected to cause more loss in area for Asphodelus aestivus and Deverra tortuosa (29\% and $7 \%$, respectively) compared to the A2A scenario $(23 \%$ and $2 \%$, respectively). For Gymnocarpos decanderus, and Haloxylon salicornicum the A1B scenario is expected to cause loss in the area of their habitat $(1.2 \%$ and $2.2 \%$, respectively), while these species are expected to gain habitat under the other two high emission scenarios (20.5 and 5.8\% under A2A scenario, respectively). Under the A1B scenario, there will be an expected reduction in the annual precipitation and precipitation of the wettest quarter compared to the average observed for the period 1950-2000 (Figure 4). On the contrary, under the $A 2 A$ and $B 2 A$ scenarios, the area is expected to experience increase in both annual precipitation and precipitation 
of wettest quarter compared to the average observed for the period 1950-2000. These factors were found to be important for the occurrence of Asphodelus aestivus, Deverra tortuosa, Gymnocarpos decanderus, and Haloxylon salicornicum (Table 4). Thymelaea hirsute seems to favor the change in climate under the three different scenarios. The species is expected to gain habitat under these scenarios. The decrease in temperature seasonality and the increase in annual precipitation, precipitation of wettest month, precipitation of wettest quarter, and precipitation of coldest quarter under A2A and B2A compared to the average for the period $1950-2000$ may explain this expected gain in habitat for Thymelaea hirsute under these scenarios. Noea mucronata is expected to be the most affected of the modeled species by the change in climate under the employed scenarios. Noea mucronata seems to be sensitive to the increase in temperature seasonality that is expected to increase under the three scenarios.

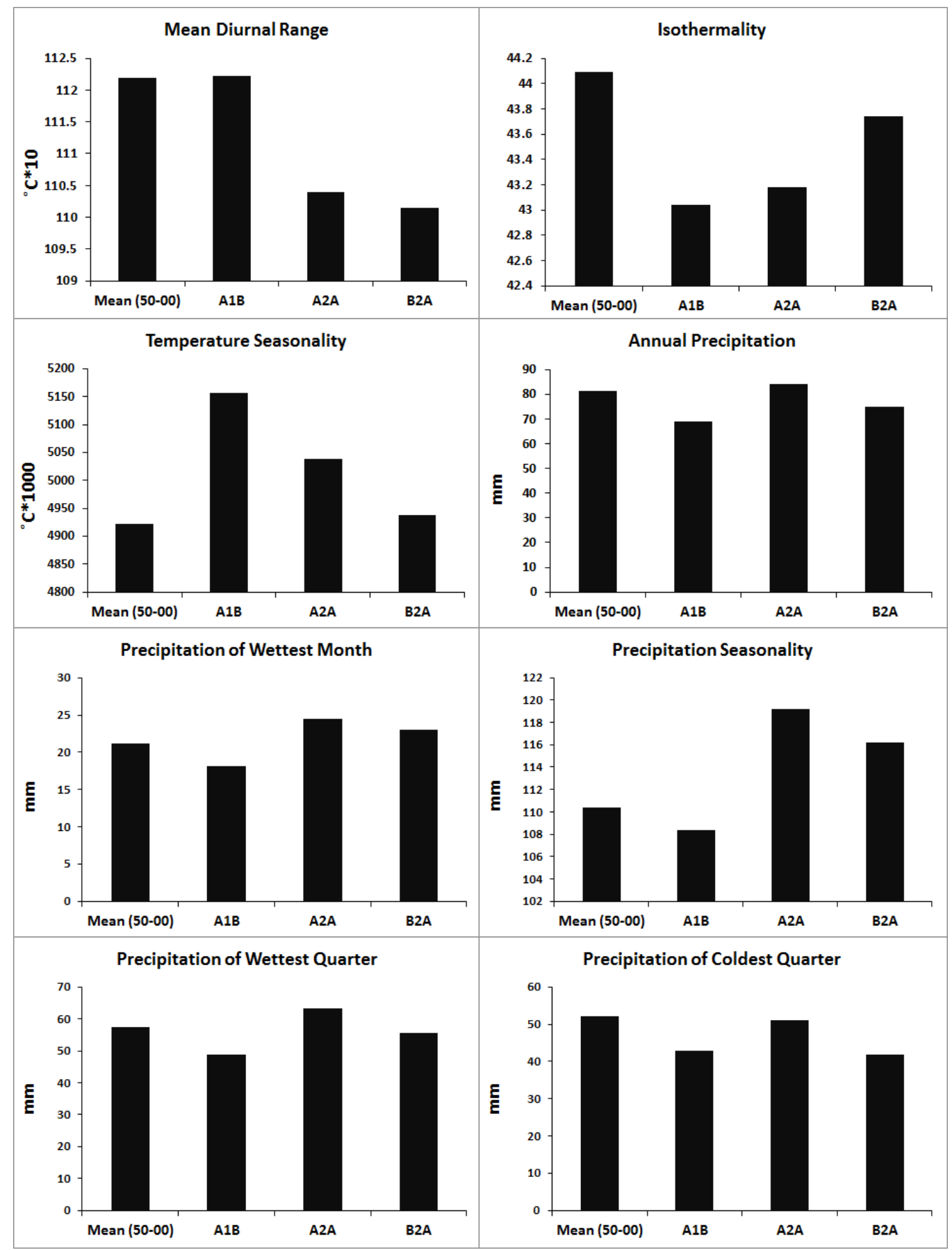

Fig .4 Mean of the climatic variables contributed in modeling plant species in the study area. The mean is calculated over the whole study area for each scenario (A1B, A2A \& B2A) and for the baseline climate that represents the mean for the period 1950- 2000. 


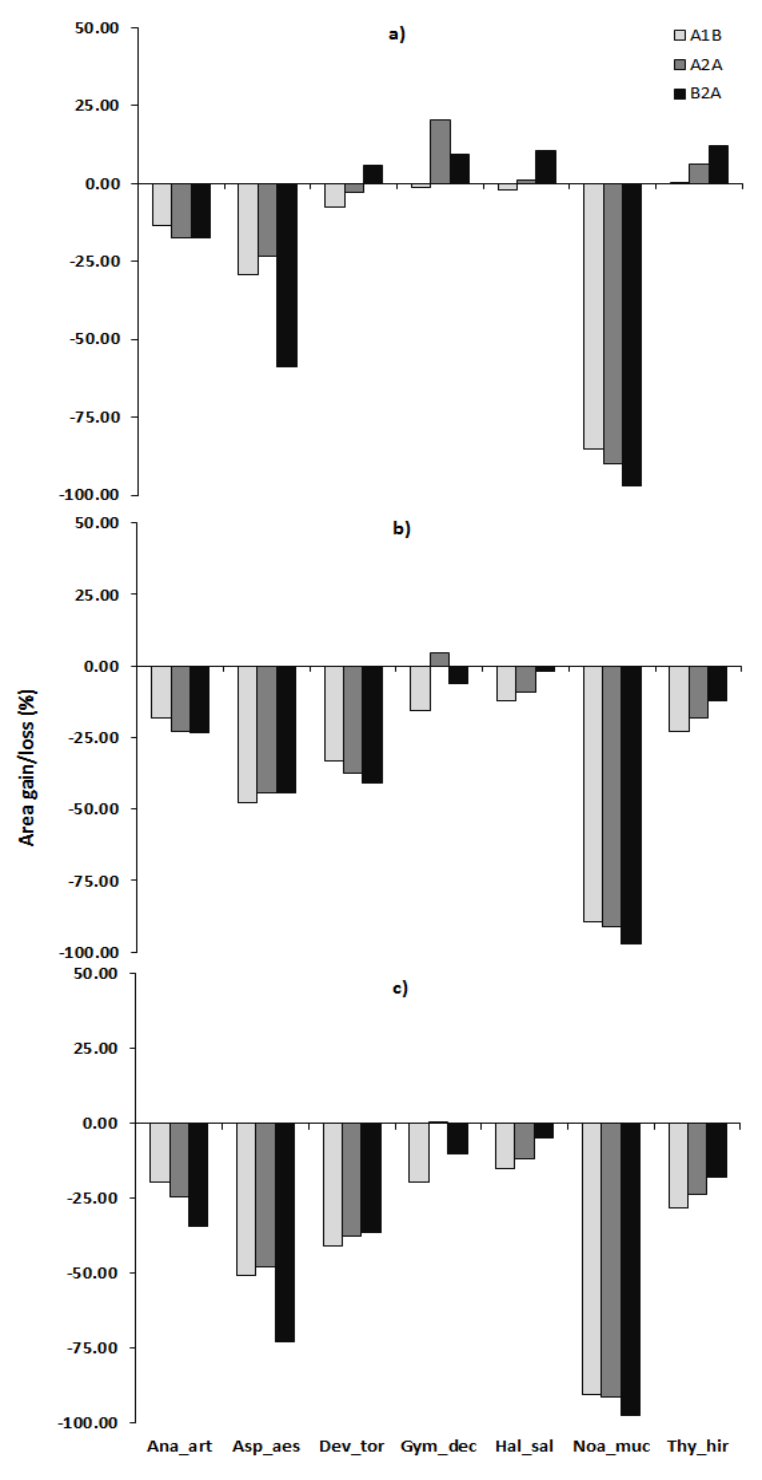

Fig .5. Gain/loss in habitat area under three climate change scenarios combined with different land use scenarios: a) no land use; b) current land use; and c) projected land use scenario by the year 2023. Gain/loss is expressed as percentage of the potential habitat area for each species under the baseline climate and no land use. See Table 3 for species binomial abbreviations.

\section{Land use and climate change combined effect}

The results show that while the change in land use in the study area resulted in loss of the area of the potential habitat for all species, the change in the climate under the employed scenarios may result in gain in area for some species. The expected loss in the area of Noaea mucronata, Asphodelus aestivus, and Anabasis articulata $(96 \%, 58 \%$, and $17 \%$, respectively) under the high emission climate change scenario B2A is higher than the expected loss under the projected change in land use by the year 2023 $(44 \%, 32 \%$, and $15 \%$, respectively). Under the scenarios of combined change in climate and land use either under the current land use or that projected by 2023, all the species are expected to suffer loss in area (Figure 5). An exception to that is Gymnocarpos decanderus, which is expected to gain area under the combined scenario of A2A emission and each of the current land use scenarios and the projected land use by 2023 . However, this increase is less than $5 \%$ of the potential area suitable for the species under A2A/2011 scenario and less than $1 \%$ under $\mathrm{A} 2 \mathrm{~A} / 2023$ scenario. The results reveal the serious fate that plant species might face under scenarios of climate and land use change. Immediate actions are needed to ensure that species as Asphodelus aestivus (Figure 6) and Noaea mucronata (Figure 7) are not declining in other places across the northwestern coast. The current study modeled the distribution of the species in part of the phytogeographical region and the status of these species needs to be known over the whole phytogeographical region. More future studies to assess the status of the species in the area, especially those of restricted distribution, are still needed. Based on the findings of these results, measures should be taken to maintain these species in the flora of the region.

\section{CONCLUSIONS}

The application of random forests to the employed climatic and land-surface parameter data proved to be successful in predicting the distribution of the plant species in the arid land landscape. The performance of the species distribution models in the current study could be attributed to the resolution of the environmental predictors used. At the landscape level the use of finer scale environmental predictors, especially climatic factors, may increase the prediction power of distribution models. The inclusion of environmental predictors that represent light proved to be of importance for the prediction of some of the modeled species in the study area.

The study found that the expected impact of the A1B, A2Aand B2A scenarios on the distribution of the modeled species is variable. In arid lands some species might be adversely affected by the change in climate under certain scenarios, while others might benefit from these changes. Land use change poses more risk on most of the species modeled compared to climate change. The impact of land use is not differential while that of climate change is. Change in land use in the area resulted in habitat loss for all the modeled species. Land use change impact could be faster and more substantial in reducing the size of 
plant species habitat. If the current trend in land use change continues, all species will continue to suffer habitat loss. The combined impact of land use and climate change pose serious threats to most of the species modeled. Under combined scenarios of change in land use as projected by 2023 and change in climate, all the species are expected to suffer loss in habitat, except Gymnocarpos decanderus.The results show that some species such as Noaea mucronata and Asphodelus aestivus may suffer serious threats in the area under the combined land use climate change scenarios. So, actions are needed to ensure that these species are not threatened across the northwestern coast and in Egypt. This also, highlights the importance of assessing the impact of land use/climate change scenarios on other species of restricted distribution in the area.The application of species distribution modeling in desert and arid lands can provide a useful tool for mapping species and assessing the impact of human induced changes on different species. Such applications are still rare, and this may be attributed to the fact that most of the arid lands and deserts are located in inaccessible or lightly populated areas. Most of these areas are also located in less developed areas where the systematic surveys of the natural resources are not conducted on a regular basis. The lack of environmental predictors of appropriate landscape resolution to be used for modeling species in such areas is another factor to be considered. The current study will promote more studies that map plant species distribution and assess the risk to important species as a result of human interference. Future studies are needed to assess the magnitude of fragmentation in each species habitat and to estimate the degree of connectivity among patches.

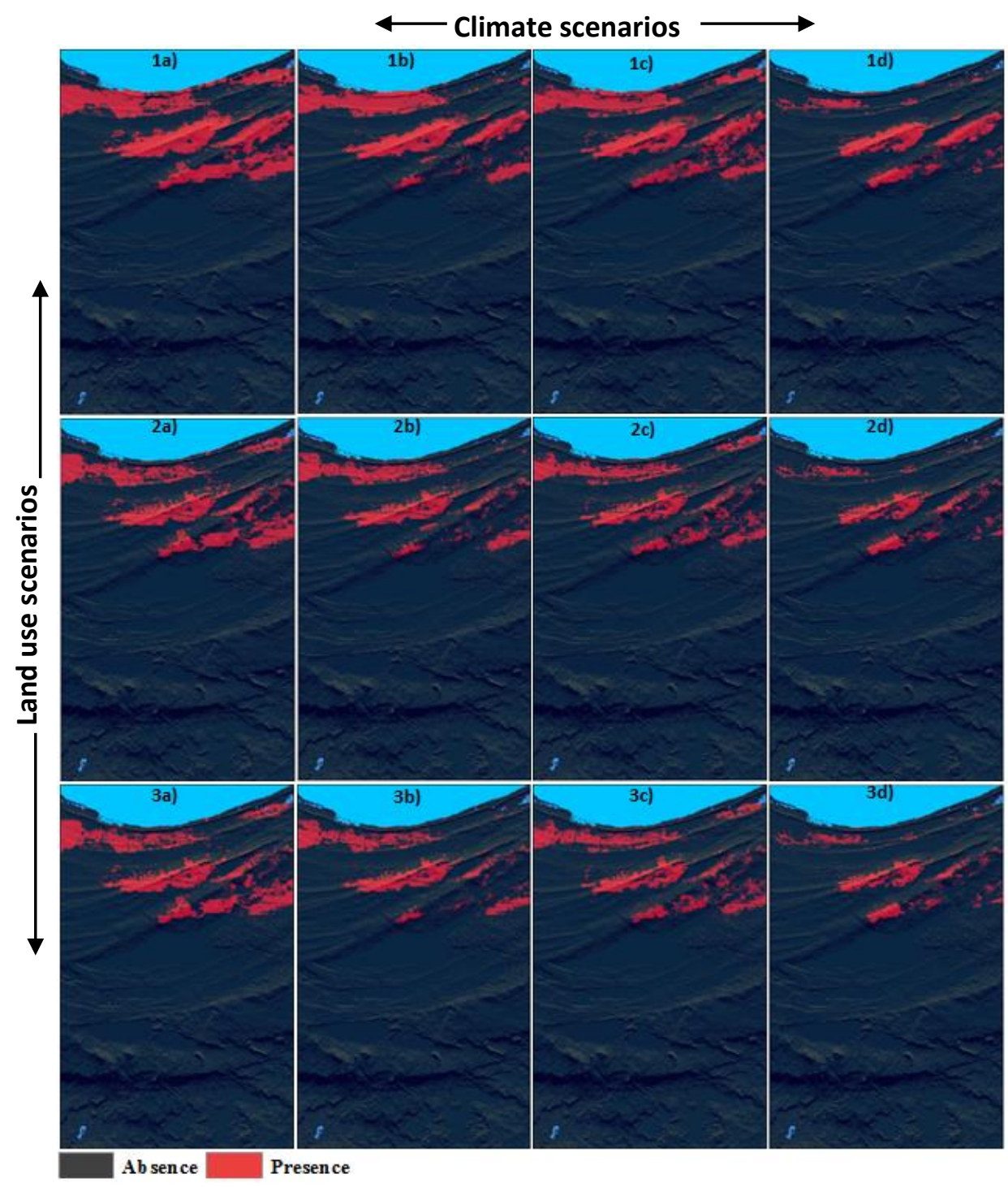

Fig .6 Potential distribution of Asphodelus aestivus under different land use and climate scenarios.1, 2 and 3 represent the natural landscape, current land use and future land use by 2023, respectively; and a, b, c and d represent the average climate (1950-2000), A1B, $\mathrm{A} 2 \mathrm{~A}$ and B2A climatic scenarios, respectively. 


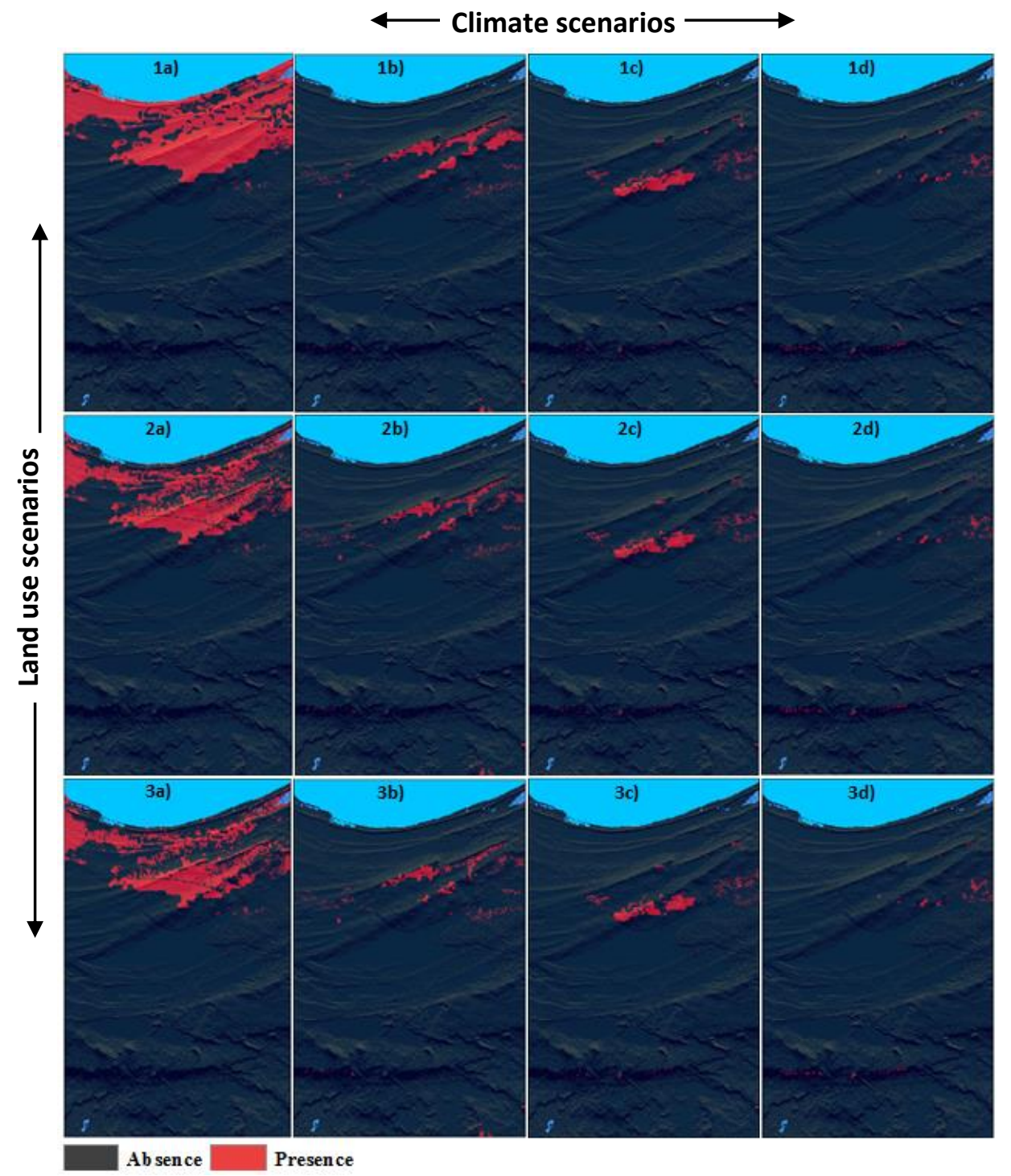

Fig .7 Potential distribution of Noaea mucronata under different land use and climate scenarios.1, 2 and 3 represent the natural landscape, current land use and future land use by 2023, respectively; and a, b, c and d represent the average climate (1950-2000), A1B, A2A and B2A climatic scenarios, respectively.

\section{REFERENCES}

[1] J. Franklin, "Predictive vegetation mapping: geographic modelling of biospatial patterns in relation to environmental gradient," Progress in Physical Geography, vol. 19, pp. 474-199, 1995.

[2] J. Elith and J. R. Leathwick, "Species distribution models: Ecological explanation and prediction across time and space," Annual Rev. Ecol. Evol. Syst., vol. 40, pp. 677-697, 2009.

[3] J. Franklin, Mapping Species Distribution: Spatial Inference and Prediction, Cambridge University Press, 2009.

[4] A. Guisan and N. E. Zimmermann, "Predictive habitat distribution models in ecology," Ecological Modeling, vol. 135, p. 147-186, 2000.

[5] A. Guisan and W. Theuriller, "Predicting species distribution: offering more than simple habitat models," Ecology Letters, vol. 8, p. 993-1009, 2005.

[6] J. Elith, S. J. Phillips, T. Hastie, M. Dudík, Y. E. Chee and C. J. Yates, "A statistical explanation of MaxEnt for ecologists," Diversity and Distributions, vol. 17, p. 43-57, 2011.

[7] P. Segurado and M. B. Araújo, Journal of Biogeography, vol. 31, pp. 1555-1568, 2004.

[8] J. Elith, C. H. Graham, P. R. Anderson, M. Dudik, S. Ferrier, A. Guisan et al., "Novel 
methods improve prediction of species' distributions from occurrence data," Ecography, vol. 29, pp. 129-151, 2006.

[9] M. J. M. and W. Jetz, "Effects of species' ecology on the accuracy of distribution models," Ecography, vol. 30, p. 135-151, 2007.

[10] P. A. Hernandez, I. Franke, S. K. Herzog, V. Pacheco, L. Paniagua, H. Quintana et al., "Predicting species distributions in poorlystudied landscapes," Biodiversity Conservation, vol. 17, pp. 1353-1366, 2008.

[11] C. Liu, M. White and G. Newell, Ecography, vol. 34, pp. 232-243, 2011.

[12] X. B. Wu and F. E. Smeins, "Multiple-scale habitat modeling approach for rare plant conservation. Landscape and Urban Planning," Landscape and Urban Planning, vol. 51, pp. 11$28,2000$.

[13] J. Franklin, "Moving beyond static species distribution models in support of conservation biogeography," Diversity and Distributions, vol. 16, p. 321-330, 2010.

[14] O. E. Sala, F. S. Chapin, J. J. Armesto, E. Berlow, J. Bloomfield, R. Dirzo et al., "Global Biodiversity Scenarios for the Year 2100," Science, vol. 287, pp. 1770-1774, 2000.

[15] R. J. Hijmans, S. E. Cameron, J. L. Parra, P. G. Jones and A. Jarvis, "Very high resolution interpolated climate surfaces for global land areas," International Journal of Climatology, vol. 25, p. 1965-1978, 2005.

[16] J. Ramirez and A. Jarvis, Disaggregation of global circulation model outputs: Decision and policy analysis working paper No. 2. CGIAR Challenge Program on Climate Change, Agriculture and Food Security, CCAFS., CGIAR Challenge Program on Climate Change, Agriculture and Food Security, CCAFS, 2010.

[17] P. Jones and P. K. Thornton, "Croppers to livestock keepers: livelihood transitions to 2050 in Africa due to climate change," Environmental Science and Policy, vol. 12, p. 427-437, 2009.

[18] A. Jarvis, H. Reuter, A. Nelson and E. Guevara,
"Hole-filled SRTM for the globe Version 4," 2008.

[19] A. Bütof, L. R. von Riedmatten, C. F. Dormann, M. Scherer-Lorenzen, E. Welk and $H$. Bruelheide, "The responses of grassland plants to experimentally simulated climate change depend on land use and region," Global Change Biology, vol. 18, p. 127-137, 2012.

[20] A. C. Hughes, C. Satasook, P. J. J. Bates, S. Bumrungsri and $\mathrm{G}$. Jones, "The projected effects of climatic and vegetation changes on the distribution and diversity of Southeast Asian bats," Global Change Biology, vol. 18, p. 18541865, 2012.

[21] J. C. Brito, A. L. Acosta, F. Álvares and F. Cuzin, "Biogeography and conservation of taxa from remote regions: An application of ecologicalniche based models and GIS to North-African Canids," Biological Conservation, vol. 142, p. 3020-3029.

[22] M. A. Ayyad and S. I. Ghabbour, "Hot desert of Egypt and Sudan," in Hot desert and arid shrublands, M. Evenari, I. B. Meir and D. Godall, Eds., Amsterdam, Elsevier, 1986, pp. 1-16.

[23] M. A. Ayyad and S. I. Ghabbour, "Dry coastal ecosystem of eastern North Africa," in Dry coastal ecosystems: Africa, America, Asia and Oceania. Ecosystems of the world, vol. 2B, E. van der Maarel, Ed., Amsterdam, Elsevier, 1993, pp. 149-201.

[24] R. Bornkamm and H. Kehl, "Landscape ecology of the western desert of Egypt," Journal of Arid Environments, vol. 17, pp. 271-277, 1989.

[25] SUMAMAD (Sustainable Management of Marginal Drylands), "Omayed Biosphere Reserve and its hinterland," submitted to National UNESCO Commission, Cairo, 2005.

[26] M. S. Abdel Razik, "Plant diversity changes in response to environmental drivers and pressures at El Omayed 'ROSELT/OSS' observatory, Egypt," in The future of the drylands, Conference on Desertification and Drylands Research, Tunisia, 19-21 June 2006, C. C. Lee and T. Schaaf, Eds., Netherlands, UNESCO, pp. 289309. 
[27] M. A. Kassas, A. Abdallah, T. Abul-Dahab, G. M. Atta, M. Esawi, H. Farouk et al., "Management Plan For Omayed Protected Area.," Med Wet Coast, Global Environment Facility and Egyptian Environment Affairs Agency (UNDP-GEFand EEAA), 2002.

[28] V. Täckholm, Students' Flora of Egypt, 2nd ed., Cairo: Cairo University, 1974, p. 888.

[29] L. Boulos, Flora of Egypt, vol. 1, Cairo: Al Hadara Publishing, 1999, p. 417.

[30] L. Boulos, Flora of Egypt, vol. 2, Cairo: Al Hadara Publishing, 2000, p. 352.

[31] L. Boulos, Flora of Egypt, vol. 3, Cairo: Al Hadara Publishing, 2002, p. 373.

[32] L. Boulos, Flora of Egypt, vol. 4, Cairo: Al Hadara Publishing, 2005, p. 617.

[33] L. Boulos, Flora of Egypt: Checklist, Cairo: Al Hadara Publishing, 2009, p. 410.

[34] M. W. Halmy, P. Gessler, J. A. Hicke and B. B. Salem, "Land use/land cover change detection and prediction in the north-western coastal desert of Egypt using Markov-CA," Applied Geography, vol. 63, pp. 101-112, 2015.

[35] S. J. Phillips, M. Dudík, J. Elith, C. H. Graham, A. Lehmann, J. Leathwick and S. Ferrier, "Sample selection bias and presence-only distribution models: implications for background and pseudo-absence data," Ecological Applications, vol. 19, pp. 181-197, 2009.

[36] M. Ayyad, Multipurpose species in Arab African countries, Cairo: UNESCO, 1998.

[37] S. Z. Heneidy and L. M. Bidak, "Potential uses of plant species of the coastal Mediterranean region, Egypt," Pakistan Journal of Biological Science, vol. 7, pp. 1010-1023, 2004.

[38] M. W. A. Halmy, Environmental risk assessment for habitats of the Egyptian northwestern coastal desert (Doctoral dissertation), University of Idaho: ProQuest Dissertations and Theses, 2012.

[39] M. W. A. Halmy and B. B. Salem, "Species conservation importance index (SCl) for comparing sites' conservation value at landscape level.," Brazilian Journal of Botany, 2015.

[40] A. T. Peterson and Y. Nakazawa, "Environmental data sets matter in ecological niche modelling: an example with Solenopsis invicta and Solenopsis richteri," Global Ecology and Biogeography, vol. 17, p. 135-144, 2008.

[41] S. Jelaska, "Vegetation mapping applications," in Goemorphometry: concepts, software, applications, T. T. Hengl and I. Evans, Eds., Elsevier, 2009, pp. 141-169.

[42] V. Olaya, "Basic land-surface parameters," in Goemorphometry: concepts, software, applications, T. Hengl and H. I. Reuter, Eds., Elsevier, 2009, pp. 141-169.

[43] I. D. Moore, P. E. Gessler, G. A. Neilsen and G. A. Petersen, "Soil attribute prediction using terrain analysis," Soil Science Society of America Journal, vol. 57, pp. 443-452, 1993.

[44] SAGA (System for Automated Geoscientific Analyses), 2011.

[45] N. E. Zimmermann and F. Kienast, "Predictive mapping of alpine grasslands in Switzerland: Species versus community approach," Journal of Vegetation Science, vol. 10, pp. 469-482, 1999.

[46] D. J. Kriticos, B. L. Webber, A. Leriche, N. Ota, I. Macadam, J. Bathols and J. Scott, "CliMond: global high resolution historical and future scenario climate surfaces for bioclimatic modelling," Methods in Ecology and Evolution, vol. 3, pp. 53-64, 2012.

[47] M. P. Austin and K. P. Van Niel, "Improving species distribution models for climate change studies: variable selection and scale," Journal of Biogeography, vol. 38, p. 1-8, 2011.

[48] J. Elith, S. J. Phillips, T. Hastie, M. Dudík, Y. E. Chee and C. J. Yates, "A statistical explanation of MaxEnt for ecologists," Diversity and Distributions, vol. 17, p. 1-15, 2010.

[49] R Development Core Team 2.13.1, "A language and environment for statistical computing.," 2011. 
[50] A. Liaw and M. Wiener, "Classification and regression by random forest," $\mathrm{R}$ News, vol. 2, pp. 18-22, 2002.

[51] A. M. Prasad, L. R. Iverson and A. Liaw, "Newer classification and regression tree techniques: Bagging and random forests for ecological prediction," Ecosystems, vol. 9, p. 181-199, 2006.

[52] D. R. Cutler, T. C. Edwards, K. H. Beard, A. Cutler, K. T. Hess, J. Gibson and J. J. Lawler, "Random forests for classification in ecology," Ecology, vol. 88, p. 2783-92, 2007.

[53] J. S. Evans and S. A. Cushman, "Gradient modeling of conifer species using random forests," Landscape Ecology, vol. 24, p. 673683, 2009.

[54] J. N. Williams, C. Seo, J. Thorne, J. K. Nelson, S. Erwin, J. M. O'Brien and M. W. Schwartz, "Using species distribution models to predict new occurrences for rare plants," Diversity and Distributions, vol. 15, p. 565-576, 2009.

[55] L. Breiman, J. H. Frriedman, R. A. Olshen and C. J. Stone, Classification and regression trees, (Belmont: Wadsworth International Group), 1984.

[56] J. A. Benediktsson, J. Chanussot and M. Fauvel, "Multiple classifier systems in remote sensing: From basics to recent developments.," in MCS 2007, vol. 4472, M. Haindl, J. Kittler and F. Roli, Eds., Berlin Heidelberg, Springer-Verlag , 2007, pp. 501-512.

[57] L. Breiman, "Random forests," Machine learning, vol. 45, pp. 5-32, 2001.

[58] P. O. Gislason, J. A. Benediktsson and J. R. Sveinsson, "Random forest classification of multisource remote sensing and geographic data.," in Geoscience and remote sensing symposium, 2004. IGARSS 04. Proceedings., 2004.

[59] P. Gislason, J. Benediktsson and J. Sveinsson, "Random forests for land cover classification," Pattern Recognition Letters, vol. 27, pp. 294300, 2006.
[60] N. Horning, "Random Forests: An algorithm for image classification and generation of continuous fields data sets.," New York, 2010.

[61] V. F. Rodriguez-Galiano, B. Ghimire, J. Rogan, M. Chica-Olmo and J. P. Rigol-Sanchez, "An assessment of the effectiveness of a random forest classifier for land-cover classification," ISPRS Journal of Photogrammetry and Remote Sensing, vol. 67, pp. 93-104, 2011.

[62] L. Zevenbergen and C. Thorne, "Quantitative analysis of land surface topography," Earth Surface Processes and Landforms, vol. 2, pp. 47-56, 1987.

[63] S. J. Riley, S. D. DeGloria and R. Elliot, "A terrain ruggedness index that quantifies topographic heterogeneity," Intermountain Journal of Sciences, vol. 5, pp. 23-27, 1999.

[64] G. J. Roloff, M. L. Donovan, D. W. Linden and M. L. Strong, "Lessons learned from using GIS to model landscape-level wildlife habitat," in Models for planning wildlife conservation in large landscapes, J. Millspaugh and F. R. Thompson III, Eds., Elsevier, 2009, pp. 287-320.

[65] O. Alloche, A. Tsoar and R. Kadmon, "Assessing the accuracy of species distribution models: Prevalence, kappa and the true skill statistic (TSS)," Journal of Applied Ecology, vol. 43, p. 1223-1232, 2006.

[66] J. Cohen, "A coefficient of agreement for nominal scales," Educational and Psychological Measurment, vol. 20, pp. 37-40, 1960.

[67] C. S. Peirce, "The numerical measure of the success of predictions," Science, vol. 4, pp. 453454, 1884.

[68] S. J. Mason and N. E. Graham, "Areas beneath the relative operating characteristics (ROC) and relative operating levels (ROL) curves statistical significance and interpretation," Quarterly Journal of the Royal Meteorological Society, vol. 128, pp. 2145-2166, 2002.

[69] M. S. Wisz, R. J. Hijmans, J. Li, A. T. Peterson, C. H. Graham and A. Guisan, "Effects of sample size on the performance of species distribution models," Diversity and Distributions, vol. 14, p. 
763-773, 2008.

[70] F. Skov and J. Svenning, "Potential impact of climatic change on the distribution of forest herbs in Europe potential of climatic on the distribution of forest herbs impact change in Europ," Ecography, vol. 27, p. 366-380.

[71] M. R. Trivedi, M. D. Morecroft, P. M. Berry and T. P. Dawson, "Potential effects of climate change on plant communities in three montane nature reserves in Scotland, UK," Biological Conservation, vol. 141, pp. 1665-1675, 2008.

[72] C. Margules and M. Austin, "Biological models for monitoring species decline: The construction and use of databases," Philosophical Transactions: Biological Sciences, vol. 344, p. 69-75, 1994.

[73] T. Dirnböck, S. Dullinger and G. Grabherret, "A regional impact assessment of climate and landuse change on Alpine vegetation," Journal of Biogeography, vol. 30, p. 401-417, 2003.

[74] H. B. Gordon, L. D. Rotstayn, J. L. McGregor, M. R. Dix, E. A. Kowalczyk, S. P. O'Farrell, L. J. Waterman, A. C. Hirst, S. G. Wilson, M. A. Collier, I. G. Watterson and T. I. Elliott, "The CSIRO Mk3 Climate System Model. Aspendale: CSIRO Atmospheric Research. CSIRO Atmospheric," CSIRO, 2002.

[75] K. H. Shaltout, "Monitoring flora of the Omayed biosphere reserve and measures of rehabilitation," in Proceedings of the International Workshop on Combating Desertification, 2002.

[76] S. Manel, H. C. Williams and S. J. Ormerod, "Evaluating presence - absence models in ecology: the need to account for prevalence," Journal of Applied Ecology, vol. 38, p. 921-931, 2001.

[77] T. Newbold, "Applications and limitations of museum data for conservation and ecology, with particular attention to species distribution models," Progress in Physical Geography, vol. 34, p. 3-22, 2010.

[78] I. Vaughan and S. J. Ormerod, "Improving the quality of distribution models for conservation by addressing shortcomings in the field collection of training data," Conservation Biology, vol. 17, pp. 1601-1611, 2003.

[79] S. A. K. Hammouda, A study of vegetation and land use in the western Mediterranean desert of Egypt. (Doctoral dissertation), Alexandria: Alexandria University, 1988, p. 194.

[80] M. A. Ayyad, "Vegetation and environment of the western Mediterranean coastal land of Egypt: The habitat of sand dunes," Journal of Ecology, vol. 61, pp. 509-523, 1973.

[81] M. A. Ayyad and M. Y. Ammar, "Relationship between Local physiographic variations and the distribution of common Mediterranean desert species," Vegetatio, vol. 27, pp. 163-176, 1973.

[82] M. A. Ayyad and R. El-Ghareeb, "Microvariations in edaphic factors and species distribution in a Mediterranean salt desert," Oikos, vol. 23, pp. 125-131, 1972.

[83] M. A. Ayyad and R. E. M. El-Ghareeb, "Salt marsh vegetation of the western Mediterranean desert of Egypt," Vegetatio, vol. 49, pp. 3-19, 1982.

[84] M. A. Ayyad and M. Y. Ammar, "Vegetation and environment of the western Mediterranean coastal land of Egypt: II. The habitat of inland ridges," Journal of Ecology, vol. 62, pp. 439-456, 1974.

[85] ROSELT/OSS, "El Omayed ROSELT/OSS Observatory," 2005.

[86] B. B. Salem, "Biosphere reserves on NorthWestern Egyptian coast, a site for monitoring biodiversity and integrated water management," in Developments in Water Science, vol. 50, A. S. Alsharhan and W. Wood, Eds., Elsevier, 2003, pp. 119-128.

[87] J. Franklin, "Predicting the distribution of shrub species in southern California from climate and terrain-derived variables," Journal of Vegetation Science, vol. 9, pp. 733-748, 1998.

[88] H. R. Akçakaya, M. A. Mccarthy and J. L. Pearce, "Linking landscape data with population viability analysis: Management options for the 
helmeted Lichenostomus melanops cassidix," Biological Conservation, vol. 73, p. 169-176, 1995.

[89] H. R. Akçakaya, "Linking population-level risk assessment with landscape and habitat models," The Science of the Total Environment, vol. 274, pp. 283-291, 2001.

[90] A. Guisan and J. Theurillat, "Equilibrium modeling of alpine plant distribution: how far can we go?," Phytocoenologia, vol. 30, p. 353-384, 2000.

[91] C. Peppler-Lisbach and B. Schröder, "Predicting the species composition of Nardus stricta communities by logistic regression modeling," Journal of Vegetation Science, vol. 15, p. 623634, 2004.

[92] C. D. Thomas, A. Cameron, R. E. Green, M.
Bakkenes, L. J. Beaumont, Y. C. Collingham and e. al., "Extinction risk from climate change," Nature, vol. 427, pp. 145-148, 2004.

[93] S. M. McMahon, S. P. Harrison, W. S. Armbruster, P. J. Bartlein, C. M. Beale, M. E. Edwards, J. Kattge and e. al., "Improving assessment and modelling of climate change impacts on global terrestrial biodiversity," Trends in Ecology and Evolution, vol. 26, p. 249-59, 2011.

[94] P. G. Jones, P. K. Thornton and J. Heinke, "Generating characteristic daily weather data using downscaled climate model data from the IPCC 's Fourth Assessment," 2009.

[95] P. G. Jones and P. K. Thornton, "Generating downscaled weather data from a suite of climate models for agricultural modelling applications," Agricultural Systems, vol. 114, p. 1-5, 2013. 